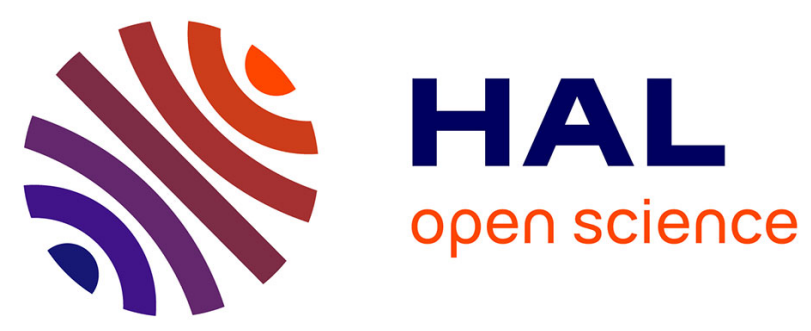

\title{
Damage investigation and modeling of 3D woven ceramic matrix composites from X-ray tomography in-situ tensile tests
}

Vincent Mazars, Olivier Caty, Guillaume Couégnat, Amine Bouterf, Stéphane G. Roux, Sébastien Denneulin, Jérôme Pailhes, Gerard L. Vignoles

\section{To cite this version:}

Vincent Mazars, Olivier Caty, Guillaume Couégnat, Amine Bouterf, Stéphane G. Roux, et al.. Damage investigation and modeling of $3 \mathrm{D}$ woven ceramic matrix composites from X-ray tomography in-situ tensile tests. Acta Materialia, 2017, 140, pp.130 - 139. 10.1016/j.actamat.2017.08.034 . hal-01593228

\section{HAL Id: hal-01593228 \\ https://hal.science/hal-01593228}

Submitted on 25 Sep 2017

HAL is a multi-disciplinary open access archive for the deposit and dissemination of scientific research documents, whether they are published or not. The documents may come from teaching and research institutions in France or abroad, or from public or private research centers.
L'archive ouverte pluridisciplinaire HAL, est destinée au dépôt et à la diffusion de documents scientifiques de niveau recherche, publiés ou non, émanant des établissements d'enseignement et de recherche français ou étrangers, des laboratoires publics ou privés. 


\title{
Damage investigation and modeling of 3D woven ceramic matrix composites from X-ray tomography in-situ tensile tests
}

\author{
Vincent Mazars ${ }^{\mathrm{a}, \mathrm{c}, *}$, Olivier Caty ${ }^{\mathrm{a}}$, Guillaume Couégnat ${ }^{\mathrm{a}}$, Amine Bouterf $^{\mathrm{b}}$, Stéphane \\ Roux ${ }^{\mathrm{b}}$, Sébastien Denneulin ${ }^{\mathrm{c}}$, Jérôme Pailhès ${ }^{\mathrm{d}}$, Gérard L Vignoles ${ }^{\mathrm{a}}$ \\ ${ }^{a}$ LCTS (Univ. de Bordeaux/CNRS/CEA/SAFRAN CERAMICS), 3 allée de la Boétie, F-33600 Pessac, \\ France \\ ${ }^{b}$ LMT (ENS Paris-Saclay/CNRS/Univ. Paris-Saclay), 61 av. President Wilson, F-94235 Cachan, France \\ ${ }^{c}$ SAFRAN CERAMICS, F-33185 Le Haillan, France \\ ${ }^{d} I 2 M$ (Arts et Métiers ParisTech/CNRS/Univ. de Bordeaux), Esplanade des Arts et Métiers, F-33405 \\ Talence, France
}

\begin{abstract}
The present paper proposes an investigation of the failure events in a melt-infiltrated $\mathrm{SiC} / \mathrm{SiC}$ composite. In-situ X-ray microtomography tensile tests were performed at room temperature and at $1250^{\circ} \mathrm{C}$ in air. Digital Volume Correlation has been used to identify the damage mechanisms within the material at increasing loads and to propose a damage scenario. Realistic finite element meshes have been constructed from the 3D images to numerically reproduce the experiments at the meso-scale. Elastic simulations exhibit stress concentrations in the planes containing the weft tows. The first cracks and subsequent damage localization were found to appear within these planes thanks to the analysis of the in-situ tomographic data.

Keywords: In-situ, Tomography, Digital Volume Correlation, Finite element, SiC/SiC composites
\end{abstract}

\section{Introduction}

Ceramic matrix composites (CMC) are high performance materials displaying remarkable properties such as damage tolerance, low density and excellent thermomechanical properties at high temperatures. They appear as promising candidates for structural

\footnotetext{
*mazars@1cts.u-bordeaux.fr

Email address: mazars@lcts.u-bordeaux.fr (Vincent Mazars)
} 
applications at elevated temperatures, e.g. for civil aeronautic engines [1]. CMC are complex materials because of their multi-scale structure and damage mechanisms. This complexity makes the service lifetime prediction required for such applications a real challenge. The understanding of the first failure events and of their propagation is of great interest for improving the design and the architecture of the material, and consequently the thermomechanical behavior. Damage mechanisms of CVI SiC/SiC composites have been largely studied and are well understood, at least at room temperature [2], [3], [4]. Experimental studies of damage mechanisms in melt infiltrated (MI) SiC/SiC composite have relied on electrical resistance change [5], acoustic emission and 2D microscopic observations [6], [7]. These studies revealed that matrix cracks initiate in weft tows and in the matrix-rich regions. At low stress, microcracks, associated with low energy acoustic signals, develop within the weft tows. When the stress increases, these microcracks propagate until they create through-thickness cracks, associated with high intensity acoustic signals. Crack initiation and propagation within the weft tows have also been observed using Scanning Electron Microscopy (SEM) [8]. This latter study has revealed damage mechanisms such as micro-debondings around the fiber/matrix interfaces and their percolation into a larger matrix crack through the weft tow.

Coupling X-ray microtomography $(\mu \mathrm{CT})$ and mechanical tests is a promising technique which has been increasingly used in the past decade to visualize and better understand the damage mechanisms within a material [9], [10]. In-situ tests are particularly relevant for materials such as $\mathrm{CMC}$ to keep the cracks open during acquisition since damages initiate at very small strain levels [11]. To observe the small cracks openings, synchrotron radiation is necessary to obtain a monochromatic, parallel and high intensity beam allowing high resolution and high signal-to-noise ratio. Analysis of the resulting images provide rich 3D information of failure events and have notably been performed for polymer-matrix composites [12], [13], [14], [15] and unidirectional ceramic matrix composites at room temperature [16], [17], [18] and at $1750^{\circ} \mathrm{C}$ [19].

Digital Volume Correlation (DVC) can be used on reconstructed X-ray tomographic data 
to measure three dimensional displacement fields [20], [21]. Based on the conservation of the local X-ray absorption coefficient, (i.e. the grey level of the 3D volume), DVC consists in minimizing residuals, defined as the difference between the deformed volume corrected by a kinematic field and the reference volume. In global DVC approaches, displacement fields are interpolated via finite element basis [22], which ensures the continuity of the displacement fields. Therefore, any discontinuity in the deformed image, such as a crack, could be detected through the study of the local residuals. Such analyses have already been conducted in [23], [24], [25], [26] to study the development of cracks. Note that at very small strain level, a regularization approach can be used to improve the DVC results [27].

Three-dimensional images obtained by $\mu \mathrm{CT}$ can be used as input data for finite element modeling (FEM), allowing to account for the exact geometry of the sample. In the case of metal foams, calculated strain and stress fields localizations have been successfully compared to the observed deformation mechanisms under loading at the cell scale [28], [29] and the strut scale [30]. FE models based on 3D images are of great interest to provide a physical explanation to the observed damage events and to develop damage laws consistent with experiments. In this study, simulations at the mesoscopic scale have been performed where the yarns are modeled as homogeneous orthotropic materials. This scale seems relevant for image-based modeling from tomographic data since it enables taking into account the reinforcement architecture, yet not being too heavy for FE calculations, as compared to micro-scale simulations. Many authors are currently developing FE models at the meso-scale for composites either by creating a virtual material [31], [32], [33] or directly using 3D images [34], [35].

The purpose of this paper is to propose a damage scenario of a $\mathrm{SiC} / \mathrm{SiC}$ at both room temperature and $1250^{\circ} \mathrm{C}$ under tensile loading using X-ray $\mu \mathrm{CT}$. Image processing and DVC residuals are used to identify the damage mechanisms at increasing loads. Elastic FE calculations directly based on the 3D images are also presented to validate the locations of the first cracks initiations within the material. 


\section{Materials and methods}

\subsection{Materials}

The investigated material is a $\mathrm{SiC} / \mathrm{SiC}$ composite developed by Safran Group. Fibrous yarns are made of $500 \mathrm{Hi}$-Nicalon S fibers with an average diameter of $12 \mu \mathrm{m}$ and woven in a 3D architecture. Fibers are coated with a thin interphase, followed by MI route.

\subsection{Experimental procedure}

Two in-situ tests have been carried out on the ID19 beamline at the European Synchrotron Radiation Facility (ESRF) in Grenoble at room temperature and $1250^{\circ} \mathrm{C}$ using a special tensile device presented on Figure 1(a). The specimens have a reduced gauge length of $10 \mathrm{~mm}$, a thickness of $3.2 \mathrm{~mm}$ and a width of $2 \mathrm{~mm}$. A hydraulic pump is used to apply the load. Load and displacements are monitored through a load cell and a displacement sensor located respectively on the lower and the upper jaw. Two glass tubes are used to bear the compression load balancing the sample traction. Tests can be performed at high temperatures by heating the samples using Joule effect (Figure 1 (b)). The sample temperature was measured with a bichromatic pyrometer. Tests were paused during approximately 20 minutes to carry out the X-ray acquisitions at $0.5 \sigma_{R}, 0.7$ $\sigma_{R}$ and $0.85 \sigma_{R}$ where $\sigma_{R}$ is the failure stress of the tested samples at room temperature and at $1250^{\circ} \mathrm{C}$. The tensile strengths of the observed specimens were very close at both considered temperatures but were approximatively only half of the corresponding values for larger macroscopic samples of a similar material [36]. Due to the small size of the specimens, the measured values of strengths should be considered with caution: this will be discussed further later in section 4.3 . The specimen was placed at $190 \mathrm{~mm}$ from the CDD camera and a $35 \mathrm{keV}$ beam energy was used. To observe the entire length of the specimen, several acquisitions were performed at a resolution of $0.9 \mu \mathrm{m}$ for each loading level, each scan containing 2160 projections, in standard absorption mode. 
(a)

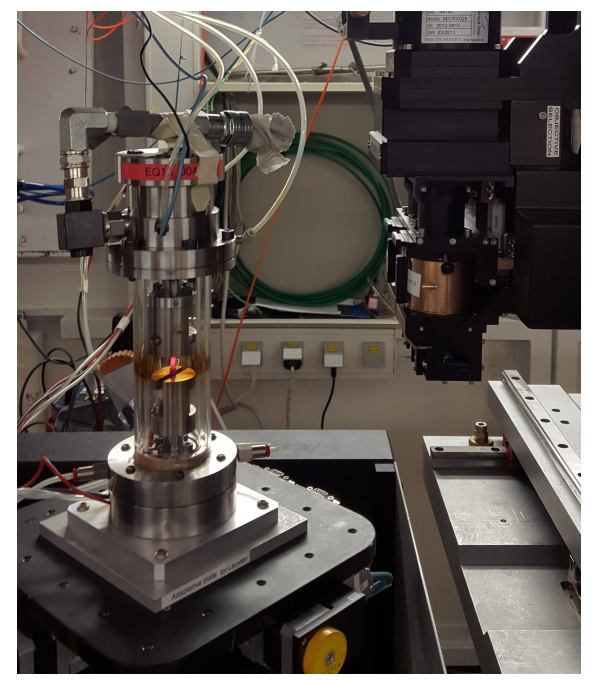

(b)

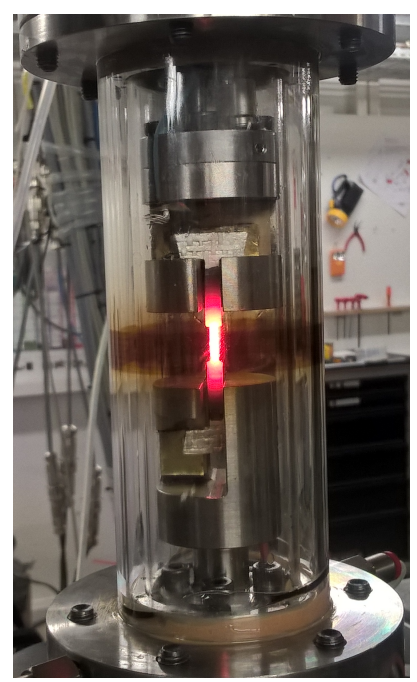

Figure 1: (a) High temperature tensile device adapted for in-situ $\mu \mathrm{CT}$ acquisitions placed on the ID19 beamline and (b) zoom on the specimen heated at $1250^{\circ} \mathrm{C}$.

\subsection{Image processing}

\subsubsection{Crack segmentation based on images differences}

A coarse crack segmentation is first proposed. Images are stitched together and downscaled by a factor of 2 . For each loading step, the rigid body motion between the reference image $f(x)$ and the deformed one $g(x)$ is partially corrected using the normalized mutual information metric [37]. The difference between the reference $f(x)$ and the registered deformed volume $g^{\prime}(x)$ is computed, $d=f-g^{\prime}$. As the cracks are mainly located in $y z$ planes where $\vec{x}$ is the loading axis, they could be extracted by performing morphological operations with a horizontal structuring element on each $x y$ slice of $d(x)$. This is followed by a morphological closing with a circular structuring element to retain only the most significant cracks. A manual control of the user is required to isolate the cracks. This coarse segmentation procedure allows to quickly visualize the network of main cracks during loading and to locate the main areas of interest.

\subsubsection{Crack segmentation based on DVC residuals}

A finer segmentation procedure based on DVC residuals is proposed hereafter. The Correli-C8R code developed by LMT Cachan has been used [25], [26], based on a weak 
formulation with C8 finite elements and a regularized approach [27]. Damage analysis is carried out on small Regions Of Interest (ROIs) of $300 \times 300 \times 300$ voxels extracted in the regions where cracks were observed with the previous coarse segmentation procedure. No rescaling is used here. The size of the elements for the calculation is 20 voxels and the length of regularization is 100 voxels. The residuals $\Phi(x)$ are obtained in each voxel as the difference between the reference image $f(x)$ and the deformed image corrected by the DVC displacement field $g(x+u(x))$. If the displacement field were a single translation, then the residuals $\Phi$ would be comparable to the previous difference $d(x)$. Residuals are filtered using a 3D non-local mean algorithm to remove noise.

\subsubsection{Yarns segmentation}

To separate the weft and warp yarns, image gradients $\nabla f$ are first computed using the spatial convolution mask defined in [38]. Then, we define the structure tensor $T(f)$ of the image in each voxel as the product $\nabla f \otimes \nabla f$. The structure tensor is a $3 \times 3$ matrix which can be diagonalized : the eigenvector $\overrightarrow{v_{1}}$ corresponding to the smallest eigenvalue $\lambda_{1}$ indicates the direction of smallest grey level variation which is expected to be aligned with the fibers direction [39], [34]. The $x$ and $y$ components of $\overrightarrow{v_{1}}$ are thresholded in order to get masks of the warp and the weft yarns. Morphological operations similar to those used in [35] are applied to improve the quality of the masks.

\subsection{Image-based FEM}

\subsubsection{FE model construction}

A FE model is constructed from the tomographic data to recreate numerically the experimental tests. Only the test carried out at $25^{\circ} \mathrm{C}$ is presented here. The tows are first segmented. An initial manual step is required, consisting in contouring by hand the section of the yarn in the middle of the specimen (Figure2(b)). These envelopes are then propagated within the masks of weft and warp yarns obtained previously. Figure 2 (c) presents the segmentation of individual yarns. The segmented images were meshed with FE tetrahedral elements since they were found to be more suitable for meso-scale analysis 
of local stress than voxel-based meshes [40]. The generalized Marching Cube routine was used to generate a conforming surface triangulation from the images and GHS3D [41] was used to provide a tetrahedral mesh of the domain. The resulting mesh is shown in Figure 2 (d) and contains approximately 5 millions of elements. The matrix is considered isotropic and homogenous. Transversely isotropic properties have been attributed to the yarns in the same way as presented in [35], using the centroid axis of each yarn to ascribe the mechanical properties. The Table 1 resumes the properties used for the model, provided by [42] at room temperature for a similar material.

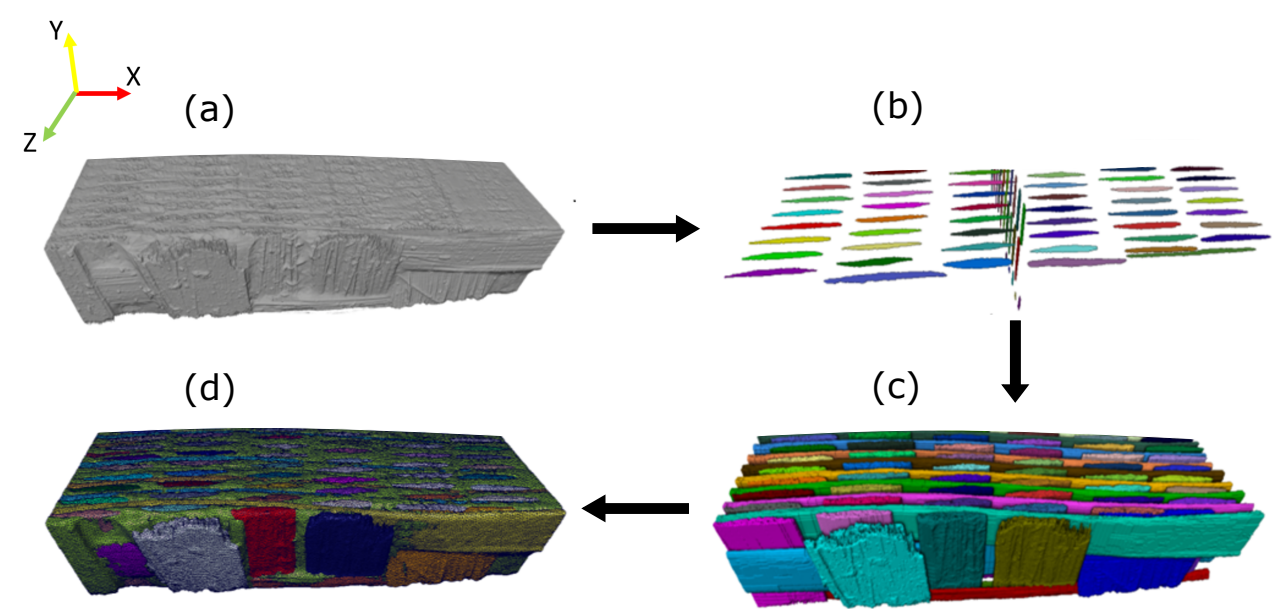

Figure 2: Methodology for creating FE models from tomography data. (a) is the reconstructed volume, (b) the contoured yarns cross section in the middle of the sample, (c) the individual yarn segmentation after propagation of envelopes and (d) final FE model obtained after meshing with tetrahedral elements. The volume of the specimen is $10 \times 2 \times 3.2 \mathrm{~mm}^{3}$

\begin{tabular}{|l|c|c|c|c|c|c|c|c|c|}
\cline { 2 - 10 } \multicolumn{1}{c|}{} & $E_{11}$ & $E_{22}$ & $E_{33}$ & $G_{12}$ & $G_{13}$ & $G_{23}$ & $v_{12}$ & $v_{13}$ & $v_{23}$ \\
\hline Yarn & 320 & 149 & 149 & 59.6 & 59.6 & 64.8 & 0.176 & 0.176 & 0.15 \\
\hline Matrix & \multicolumn{3}{|c}{310} & \multicolumn{3}{c}{132.5} & \multicolumn{3}{c}{0.17} \\
\hline
\end{tabular}

Table 1: Meso-scale mechanical properties at room temperature where $\mathrm{E}$ and $\mathrm{G}$ are expressed in GPa and $v$ is the Poisson ratio coefficient. (Values from [42])

\subsubsection{Boundary conditions}

DVC has also been used to evaluate the real boundary conditions (BCs) applied to the specimen and to quantify the difference between the expected and the actual BCs. ROIs 
are extracted around the top and the bottom of the specimen for each loading step. As a first approximation, the displacements are linearized by fitting the three displacement field components to a plane. The resulting BCs are eventually applied to the corresponding nodes of the FE model. Elastic FE simulations have been performed using Abaqus 6.12.

\section{Results}

\subsection{Damage analysis}

\subsubsection{Main cracks network}

The main crack network obtained using the coarse crack segmentation procedure is presented Figure 3 for increasing loads at room temperature and at $1250^{\circ} \mathrm{C}$. In both cases, cracks initiate near the free surfaces and propagate perpendicularly to the loading axis. Once a crack is initiated, multiple microcracks develop in its vicinity (up to $20 \mathrm{~mm}^{-3}$ for $\left.0.85 \sigma_{R}\right)$. This leads to an uneven distribution of cracks, that appear clustered in some particular regions (labelled with stars in Fig. 3) while other ones remain crack free. The location of the final failure is indicated in Figure 3 by a black ellipse in the initial volume. As expected, the final fracture appears both at $25^{\circ} \mathrm{C}$ and $1250^{\circ} \mathrm{C}$ in one of the highly damaged zones.

To better understand how the architecture of the material influences the development of the crack network, Figure 4 shows the number of voxels belonging to cracks (in red) and to weft yarns (in green) projected along the length of the sample location for increasing loads at (a) $25^{\circ} \mathrm{C}$ and (b) $1250^{\circ} \mathrm{C}$. The peaks of the green curves correspond to the location of the weft planes. At room temperature, most of the cracks are located in these planes. As the load increases, cracks proliferate in these particular areas. 


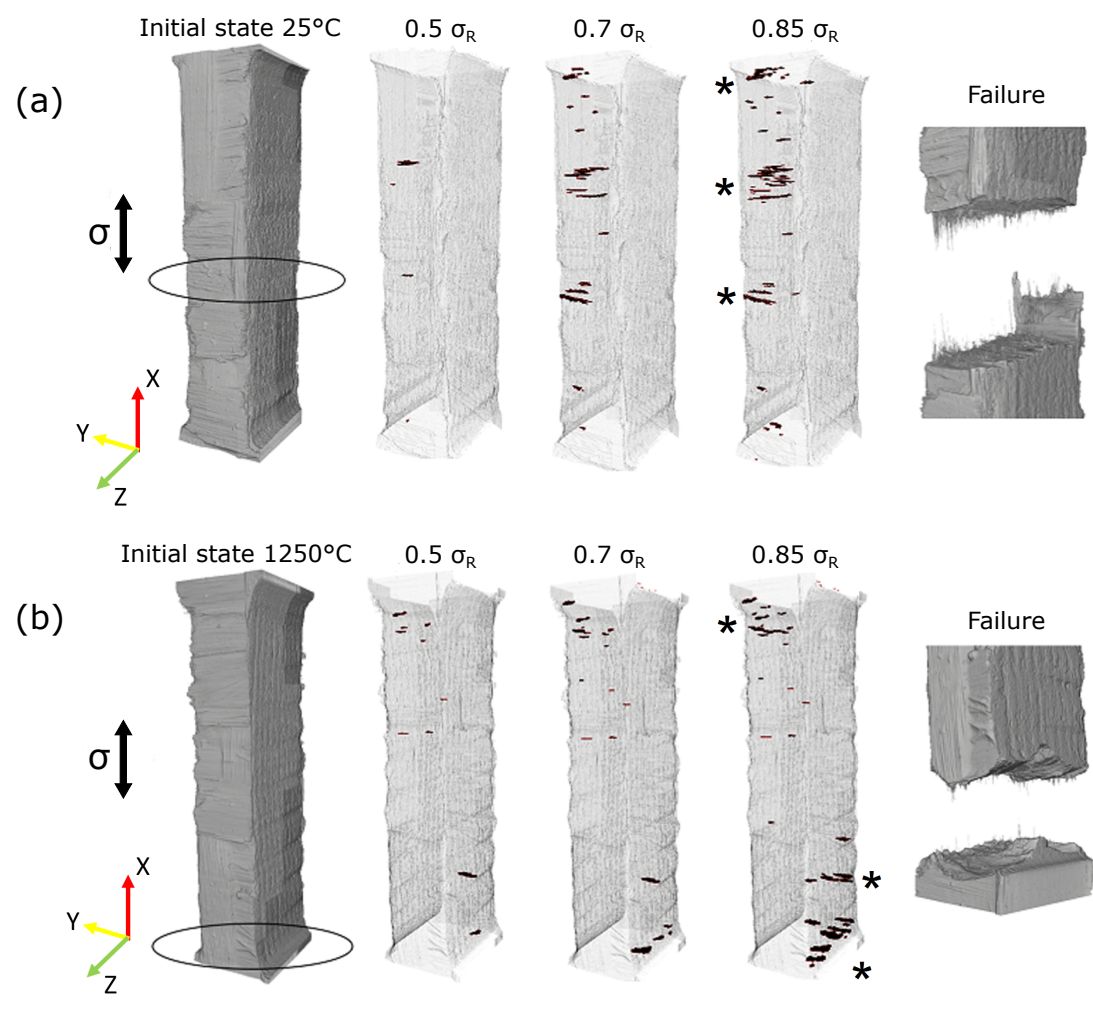

Figure 3: Crack network development at increasing loads states at (a) room temperature and (b) $1250^{\circ} \mathrm{C}$. On the initial states (left), a black ellipse corresponds to the areas where the final fracture occurred (right). The volume of both specimens is $10 \times 2 \times 3.2 \mathrm{~mm}^{3}$

(a)
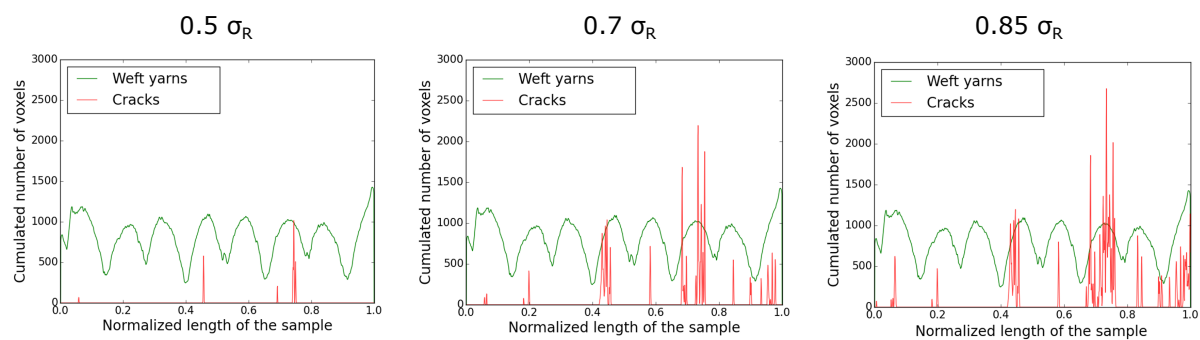

(b)
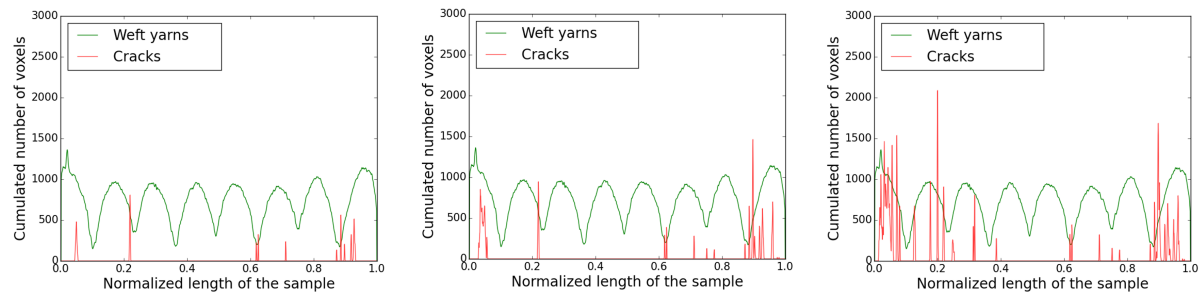

Figure 4: Projection of the number of voxels corresponding to cracks (in red) and weft yarns (in green) along the sample length at (a) room temperature and (b) $1250^{\circ} \mathrm{C}$ at increasing load states. 


\subsubsection{DVC residuals results}

DVC residuals are analyzed to characterize the damage events in a more local manner. Figure 5 presents (a) the reference image $f(x)$ of a $\mu \mathrm{CT}$ slice of the sample tested at $25^{\circ} \mathrm{C}$, (b) the deformed images corrected by the displacement field $g(x+u(x))$ obtained by DVC at increasing loads, and (c) the corresponding residuals $\Phi(x)$. Before propagating in the volume, cracks initiate in the weft yarns. Cracks initiation can hardly be seen on the deformed images, but appear clearly on the residuals fields. When load increases, other matrix cracks initiate in the crossing between yarns and propagate to matrix rich regions or longitudinal yarns until they interact and merge themselves into a larger through-thickness crack.

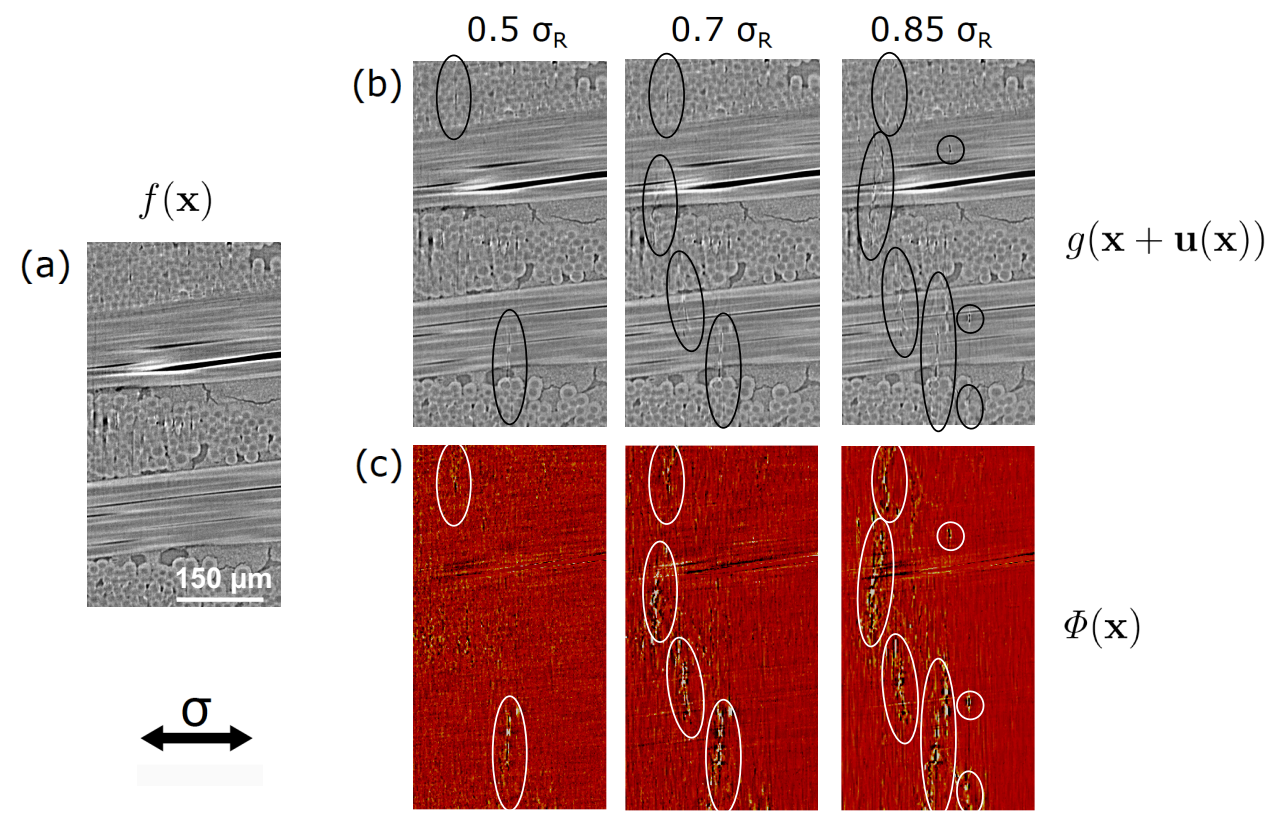

Figure 5: $\mu \mathrm{CT}$ slice of the sample tested at room temperature : (a) reference image, (b) deformed images at several load steps corrected by a DVC displacement field and (c) the corresponding residuals fields. Black ellipses highlight the observed damage events

Other damage events can be observed thanks to the DVC residuals. Fiber/matrix debondings are detected at high temperature in longitudinal tows (Figure 6(a)). Fiber failures are also easily detected with residuals (Figure 6(b)). At high temperature, fibers mostly break in the main crack plane while at room temperature, the are spread over 200 $\mu \mathrm{m}$ from the crack as shown in Figure 7(a). This has been confirmed by post-mortem 
SEM observations that clearly show a smoother fracture surface at $1250^{\circ} \mathrm{C}$ than at room temperature (Figure 7(b)).

(a)

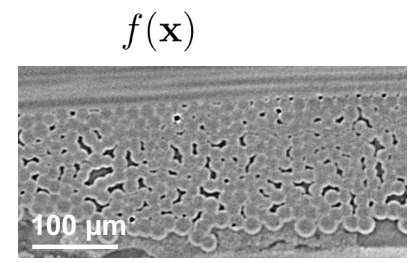

(b)

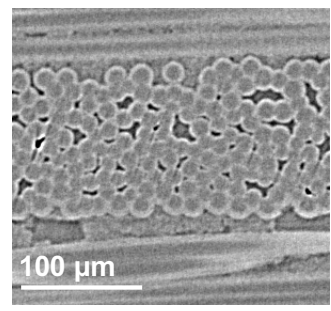

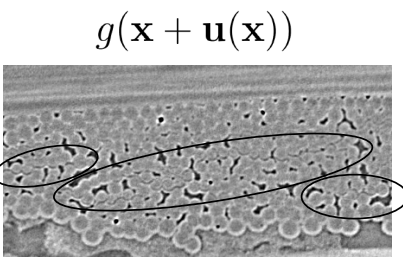

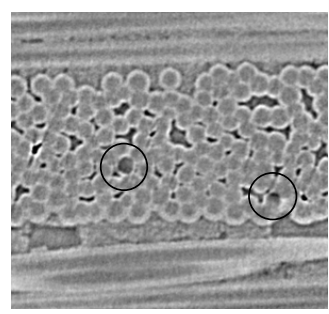

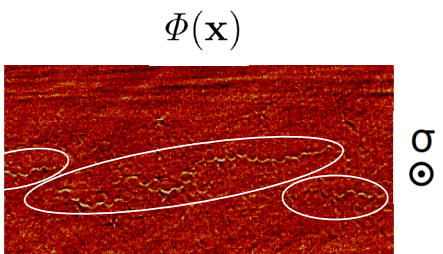

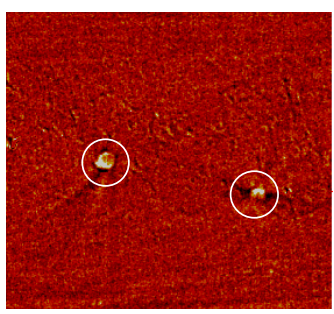

Figure 6: $\mu \mathrm{CT}$ slices of reference images (left), deformed images corrected by a DVC displacement field (middle) and corresponding residuals (right). They show (a) debondings in longitudinal yarn (black ellipse) at $1250^{\circ} \mathrm{C}$ and (b) fiber failures (black ellipse) at room temperature

(a)
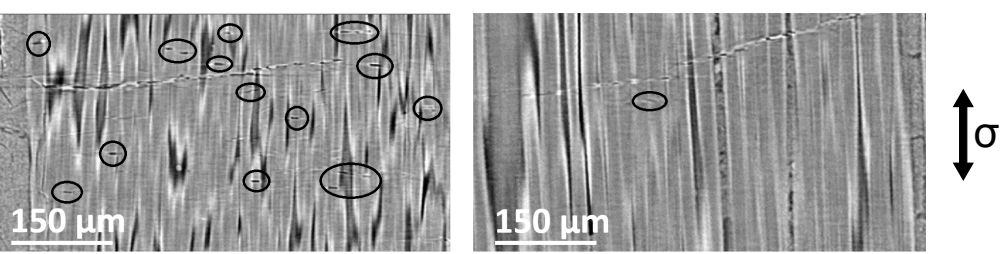

(b)
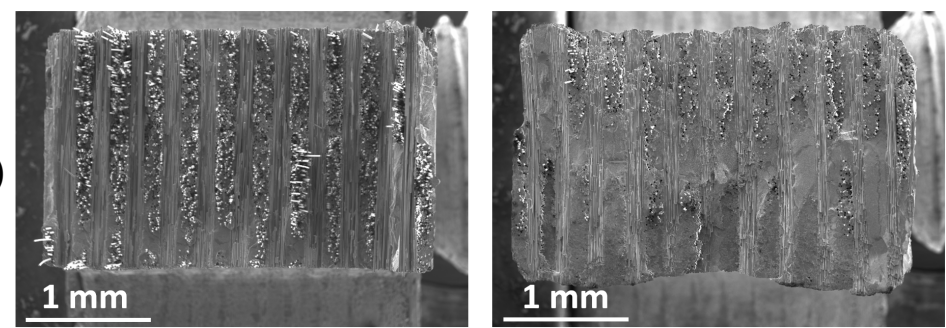

Figure 7: (a) $\mu \mathrm{CT}$ slices at $0.85 \sigma_{R}$ of the sample tested at room temperature (left) and at $1250^{\circ} \mathrm{C}$ (right) showing a transverse crack. Fiber failures outside the main crack are surrounded by black ellipses. (b) Fracture surfaces at room temperature (left) and $1250^{\circ} \mathrm{C}$ (right).

Subvolume of the residuals at $25^{\circ} \mathrm{C}$ was extracted and thresholded for two different orientations (Figure 8 (b)). These images bring further insight into the shape of the cracks. In particular, cracks appear to be not perfectly plane and exhibit deviations and branching. At $0.7 \sigma_{R}$, fiber failures start to be noticeable around the main crack. Typical fiber failures penny-shape are illustrated Figure 8 (c). 
(a)

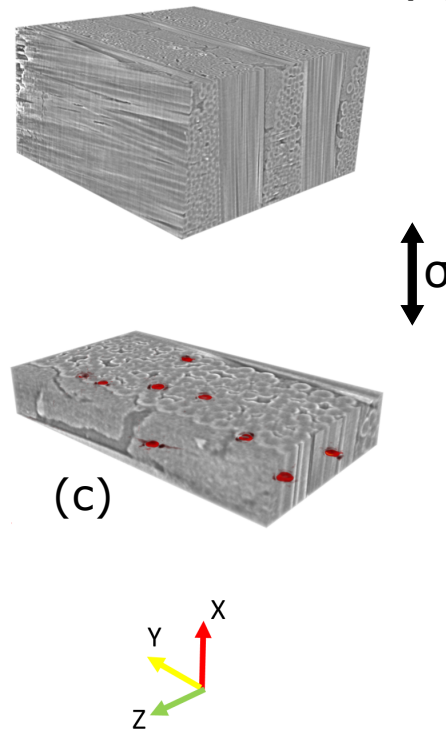

(b)

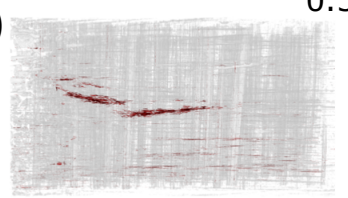

$0.5 \sigma_{\mathrm{R}}$

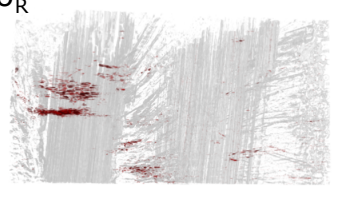

$0.7 \sigma_{\mathrm{R}}$

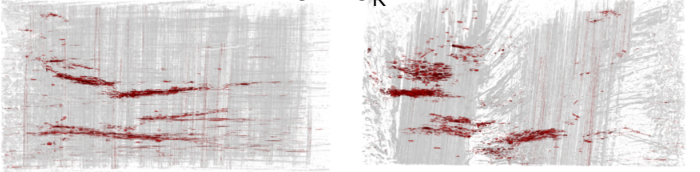

$0.85 \sigma_{\mathrm{R}}$
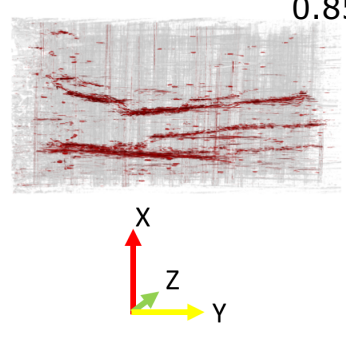

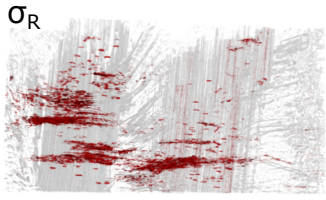

$\stackrel{Y}{\longrightarrow}_{Z}$

Figure 8: (a) Subvolume of the sample tested at room temperature $(340 \times 640 \times 640$ voxels), (b) 3D filtered thresholded residuals at increasing load states for two different orientations superimposed to the subvolume (in light grey) and (c) zoom on fiber breakage (in red) of an extracted subvolume $(60 \times 350 \times 200$ voxels)

\subsection{FE results}

Figure 9 (a) presents the $\mathrm{FE}$ model of the central part of the specimen at $25^{\circ} \mathrm{C}$. On the top and the bottom of the FE model (indicated by stars on Figure 9 (a)), the three components $U_{x}, U_{y}, U_{z}$ (normalized by $U_{R}=\epsilon_{R} \times L_{\text {sample }}$ ) of the displacement fields obtained by DVC are plotted (red dots) as well as the best fitting planes for a load of 0.5 $\sigma_{R}$ (Figure 9 (b)). We define $\delta U_{x}(y, z)$ as the difference between $U_{x}(y, z) / U_{R}$ evaluated at the top of the specimen and $U_{x}(y, z) / U_{R}$ evaluated at the bottom. The average of $\delta U_{x}$ gives a positive value, which is consistent with a tensile test in the $\vec{x}$ direction. However, $\delta U_{x}$ is clearly not uniform which indicates flexion within the sample. The values of $U_{y}$ and $U_{z}$ calculated at the top of the specimen exhibit a variation respectively in the $\vec{y}$ and in the $\vec{z}$ directions. On the contrary, $U_{y}$ and $U_{z}$ evaluated at the bottom of the specimen show a gradient respectively in the $\vec{z}$ and in the $\vec{y}$ directions which give rise to a twisting moment around the $\vec{x}$ axis and to shear stress on the $y z$ plane. The sample is therefore subjected to a complex tensile/flexural/torsional loading.

The same analysis has been performed on the specimen loaded at $1250^{\circ} \mathrm{C}$. The boundary 
conditions evaluated by DVC at $0.5 \sigma_{R}$ at room temperature and at $1250^{\circ} \mathrm{C}$ have been applied to an homogenous macroscopic FE model of the sample. Figure 10 shows the normalized strain $\epsilon_{11}$ on the deformed shape of the models where the deformations have been magnified by a factor 30. The non-uniform loading due to the real BCs is clearly visible since the sample should have remained straight in the case of a perfect tensile test. However, the strain fields and the deformed shapes of the samples are very similar at room temperature and at $1250^{\circ} \mathrm{C}$, which indicates that the experiment was quite reproductible and that the observed damage events can be compared.

(a)

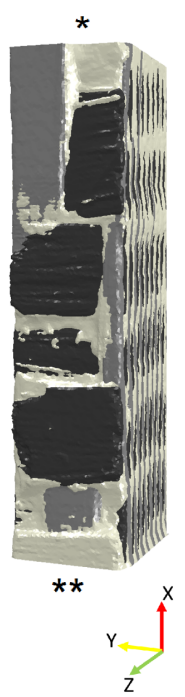

(b) Normalized DVC displacement components evaluated in *
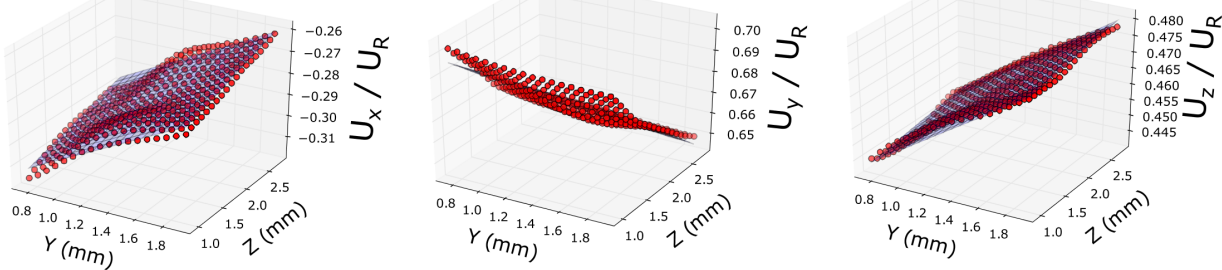

Normalized DVC displacement components evaluated in **

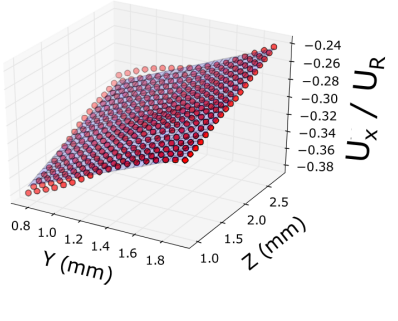

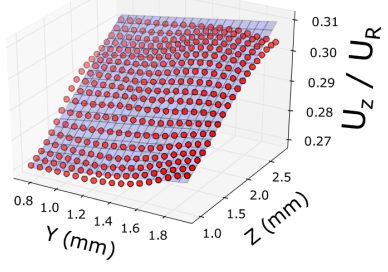

Figure 9: (a) FE model at room temperature before calculation, (b) Displacement field components calculated with DVC at $0.5 \sigma_{R}$ (red dots) at the top and the bottom of the specimen (respectively* and ** in (a)). The blue planes fitting these points at best are applied as BCs in the FE model

FE calculations on the meso scale were only performed on the specimen at room temperature depicted Figure 9 (a). Figure 11 presents a slice of the specimen tested at $25^{\circ} \mathrm{C}$ for increasing loads (Figure 11 (b)) and the local strain field $\epsilon_{11}$ obtained from the FE calculations on the corresponding slice (Figure 11(c)). The zones which experience higher strain in the $\vec{x}$ direction (black ellipse) are consistent with the observed asymmetrical crack development visible on Figure 11(b). Weft planes display higher strain levels which is consistent with the observations of Figure 4 In the zone of excess tensile stress, 
(a)

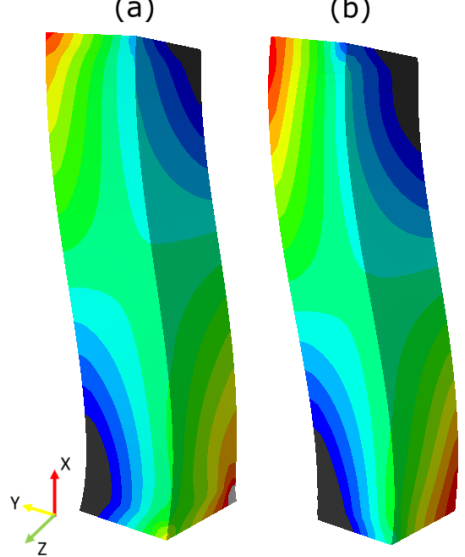

Figure 10: Strain fields $\epsilon_{11}$ on the deformed shape of the FE homogeneous model with real boundary conditions evaluated by DVC at $0.5 \sigma_{R}$ (a) at room temperature and (b) at $1250^{\circ} \mathrm{C}$.

the first cracks appear in the transverse tow at a local strain level $\epsilon_{11}$ estimated for a global load of $0.5 \sigma_{R}$. Strains are also higher around the notches at the surface of the specimen (indicated by black arrows Figure 11 (c) at $0.7 \sigma_{R}$ ). These notches come from the texture of the material and are accurately reproduced by the FE model.

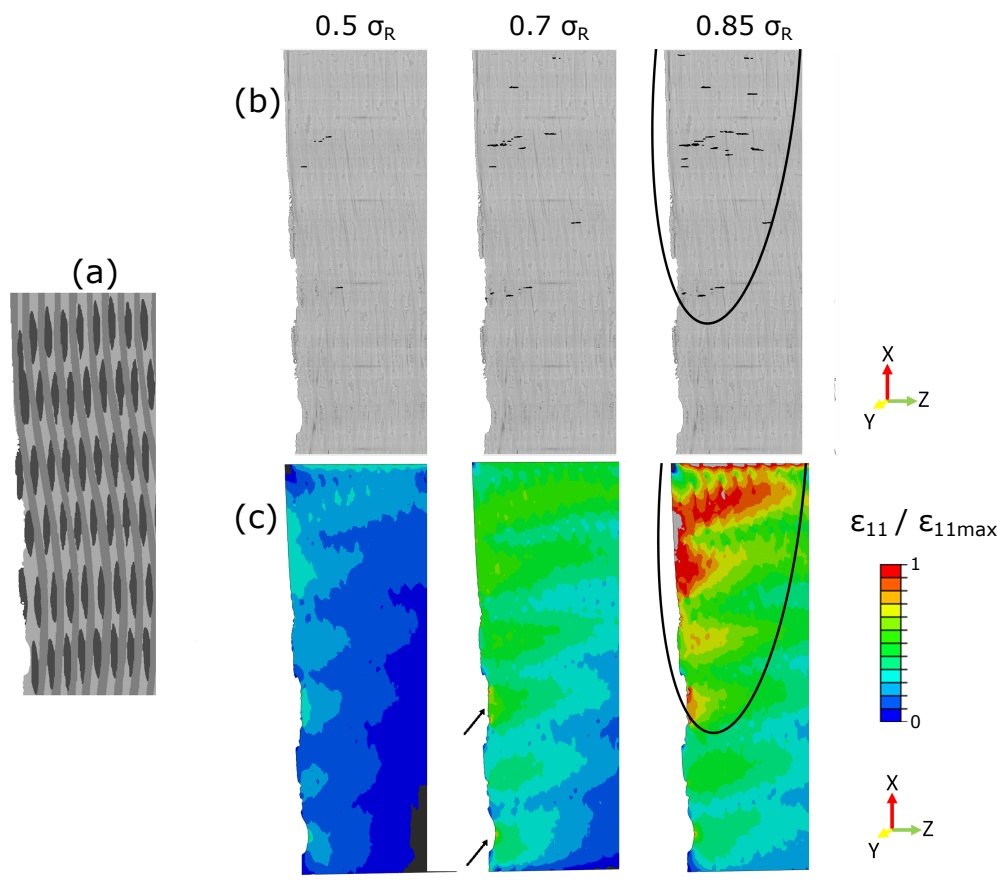

Figure 11: (a) 2D segmented slice of the sample tested at $25^{\circ} \mathrm{C}$, (b) same slice at increasing loads where the cracks are highlighted in black and (b) corresponding normalized strain fields calculated by FE. The black ellipses show the side of the specimen where the cracks are mainly located and where the strains are higher. The black arrows highlight higher strains around the notches at the surface 


\section{Discussion}

\subsection{Damage identification at $25^{\circ} \mathrm{C}$ and $1250^{\circ} \mathrm{C}$}

The tensile device described here offers the possibility to perform tests at temperatures very close to the real service conditions. DVC residuals showed that the first matrix cracks initiate in the transverse yarns, both at $25^{\circ} \mathrm{C}$ and at $1250^{\circ} \mathrm{C}$, and mainly develop within the transverse yarns planes. This is consistent with the conclusions of Morscher [6], [7] for a similar material, although he also observed cracks nucleation in the matrix-rich regions. In our case, matrix cracks propagate from weft yarns to matrix-rich regions or to longitudinal yarns. After damage initiation, differences have been noted between the tests at room temperature and at $1250^{\circ} \mathrm{C}$. In particular, fiber/matrix debondings within longitudinal yarns have only been observed at high temperature and could be attributed to the thermal history of the material. In contrast to room temperature, almost no fiber failures are observed outside the main crack at $1250^{\circ} \mathrm{C}$ (see Figure 7). In both cases, the oxidizing species can penetrate in the material due to the crack network at high damage level. However, the oxidation kinetics become more significant at elevated temperature [43], which results in a more brittle failure at $1250^{\circ} \mathrm{C}$ than at room temperature. These differences observed in damage mechanisms could be related to the decrease in strength and strain to failure with temperature for macroscopic tensile tests performed on a similar $\mathrm{SiC} / \mathrm{SiC}$ composite [36].

\subsection{Coupled in-situ tests and image-based FE methodology}

After applying the BCs evaluated by DVC to the FE model constructed from the tomography data at the meso-scale, the resulting strain fields are consistent with the location of the first cracks observed experimentally. It is not the case with a perfect tensile test simulation. We underline here the necessity to take into account the real BCs for an accurate image-based FE simulation. Of similar importance, a simulation where the specimen is treated as a homogeneous material is insufficient to accurately predict the first failure events, even by applying the BCs evaluated with DVC. It is therefore mandatory to 
combine a high-fidelity FE model at the meso-scale and the real BCs to be able to predict the location of the first failure events within the material. Planes containing weft yarns were found to be more severely loaded : it is therefore not surprising that the first cracks were observed in these areas. The local strain level $\epsilon_{11}$ in the transverse tows at which the first cracks appear is estimated for a global load of $0.5 \sigma_{R}$ in the zone of excess tensile stress. This value is however obtained with a given set of properties for the yarns and the matrix provided by literature [42]. A finer identification of these properties, in particular by a multi-scale identification procedure [44], [45], [46] may lead to a slightly different estimate. Moreover, DVC calculations revealed that the performed tests were actually a combination of non-uniform traction, flexion and torsion. Under such a complex loading, we could expect that the damage mechanisms would slightly differ from a perfect tensile test.

\subsection{Limitations}

Although quantitative damage mechanisms can be extracted from the in-situ tomographic imaging and image processing, some data cannot be retrieved. Crack openings in the investigated material are very small, roughly the size of a voxel. They can be observed mainly due to the phase contrast phenomenon which enhances the contrast at interfaces. Therefore, crack opening widths cannot be precisely quantified. Complementary tests have to be performed, such as those realized by [8] under SEM to quantify matrix crack opening widths. These data would be of prime interest for developing coupled thermomechanical and physico-chemical models also taking into account the oxidation mechanisms.

The tested volume $\left(10 \times 2 \times 3.2 \mathrm{~mm}^{3}\right)$ of the investigated samples is below the geometric Representative Elementary Volume (RVE). Due to these small dimensions, the representativity of the performed tests may be questioned. First, surface defects are proportionally more influential on the onset of damage as compared to larger ones. The influence of the distance to the free surfaces is also questionable about the representativity of the effective stress state of the tested volume as compared to the same volume inside a bigger sample. 
This effect is likely to be limited in the case of a perfect tensile test, but not in the case of a complex mechanical loading. As mentioned before, the measured strengths at room temperature and at $1250^{\circ} \mathrm{C}$ are significantly lower compared to those obtained for macroscopic samples. This peculiar behavior is related to the small dimensions of the samples ( $2 \mathrm{~mm}$ width) with respect to the size of a yarn. This limited size impedes the stress transfer within the material which makes the sample more sensitive to the first damage events. As presented Figure 10 the specimens experienced a complex multiaxial loading, which could also partially explain the lower strength values. Due to the small dimensions of the samples and the non-uniform mechanical loading, the realized in-situ tests cannot be used directly to characterize the mechanical behavior of the nominal material and must be used in addition of standard macroscopic tests. However, it provides an excellent way to identify the damage mechanisms and especially the first ones, of prime interest for the design of the material.

\section{Conclusions and outlook}

In-situ tensile tests have been carried out at both room temperature and at $1250^{\circ} \mathrm{C}$ under $\mu \mathrm{CT}$ on $\mathrm{SiC} / \mathrm{SiC}$ materials. The study of DVC residuals revealed the apparition and the evolution of damage patterns within the material and allowed to propose a qualitative damage scenario. Matrix cracks first initiate in weft yarns, develop and proliferate in the weft planes until they coalesce and create a through-thickness failure. The location of the first matrix cracks is consistent with the results of FE simulations at the mesoscale which show higher strain at the yarn crossings. The tests also revealed that, while fibers break outside the crack planes at $25^{\circ} \mathrm{C}$, they break within the main crack plane at $1250^{\circ} \mathrm{C}$. Beside the qualitative proposed scenario, the image processing tools presented in this paper enable extracting quantitative data such as crack growth kinetics or fiber failures kinetics, of great interest for damage models development. The image-based FE methodology employed here proved its interest : it allowed to predict where the first cracks would appear in the material, as confirmed by this experimental investigation. 
Further works include the development of non-linear FE models to predict not only the location of the first cracks, but also their propagation. Secondly, the investigated samples here are small-sized and it would be desirable to proceed to further investigations on larger samples. Finally, crack opening widths cannot be evaluated yet, even with the high resolution employed in this study. Additional in-situ SEM tensile tests could be relevant to estimate the cracks openings. This would help to develop high temperature models taking into account chemo-mechanical coupling, e.g. subcritical crack growth in oxidizing environments at elevated temperatures.

\section{Acknowledgements}

Safran group is acknowledged for funding the $\mathrm{PhD}$ of Vincent Mazars and providing the CMC samples. For the development of the in-situ tensile test machine, the present study benefited from the help of the I2M laboratory, in particular Fabrice Prince, JeanMarie Diaz and Alain Sommier and the work of Félicien Auguin, Bruno Vecina, Matthias Gosset and Jonathan Jouveau during their internships. For in-situ tensile tests, the authors are grateful to the ID19 beamline team at ESRF, and in particular to Elodie Boller for image acquisitions. The authors acknowledge Kakmol Nong (Safran group) and Thomas Philippe (Safran group) for their help in the experiment at ESRF. We finally want to thank Muriel Alrivie (LCTS) and Rémi Bertrand (LCTS) for acquiring the SEM images.

\section{References}

[1] P. Spriet, G. Habarou, Applications of CMCs to Turbojet Engines: Overview of the SEP Experience, in: Ceramic and Metal Matrix Composites, Vol. 127 of Key Engineering Materials, Trans Tech Publications, 1996, pp. 1267-1276. doi:10. 4028/wWW. scientific.net/KEM.127-131.1267.

[2] J. Lamon, Micromechanics-based approach to the mechanical behavior of brittlematrix composites, Composites Science and Technology 61 (15) (2001) 2259-2272. 
[3] J. Lamon, Chemical vapor infiltrated $\mathrm{SiC} / \mathrm{SiC}$ composites (CVI SiC/SiC), in: Handbook of ceramic composites, Springer, 2005, pp. 55-76.

[4] E. Grippon, Endommagement et microfissuration d'un composite à matrice céramique tissée 3D : approche multi-échelle et évaluation ultrasonore, Ph.D. thesis, Ecole doctorale Science et Physique pour l'Ingénieur Université de Bordeaux 1 (2013).

[5] T. Sujidkul, C. E. Smith, Z. Ma, G. N. Morscher, Z. Xia, Correlating electrical resistance change with mechanical damage in woven $\mathrm{SiC} / \mathrm{SiC}$ composites: Experiment and modeling, Journal of the American Ceramic Society 97 (9) (2014) 2936-2942. doi: $10.1111 /$ jace. 13019

[6] G. Morscher, Stress-dependent matrix cracking in 2D woven SiC-fiber reinforced melt-infiltrated SiC matrix composites, Composites Science and Technology 64 (9) (2003) 1311-1319. doi:10.1016/j.compscitech.2003.10.022.

[7] G. N. Morscher, H. M. Yun, J. A. DiCarlo, In-plane cracking behavior and ultimate strength for 2D woven and braided melt-infiltrated $\mathrm{SiC} / \mathrm{SiC}$ composites tensile loaded in off-axis fiber directions, Journal of the American Ceramic Society 90 (10) (2007) 3185-3193. doi : 10.1111/j.1551-2916.2007.01887.x.

[8] J. Tracy, Multi-scale investigation of damage mechanisms in SiC Ceramic Matrix Composites, Ph.D. thesis, University of Michigan (2014).

[9] E. Maire, P. Withers, Quantitative X-ray tomography, International Materials Reviews 59 (1) (2014) 1-43.

[10] J. Y. Buffiere, E. Maire, J. Adrien, J. P. Masse, E. Boller, In situ experiments with X-ray tomography: an attractive tool for experimental mechanics, Experimental Mechanics 50 (3) (2010) 289-305. doi:10.1007/s11340-010-9333-7. 
[11] R. Böhm, J. Stiller, T. Behnisch, M. Zscheyge, R. Protz, S. Radloff, M. Gude, W. Hufenbach, A quantitative comparison of the capabilities of in situ computed tomography and conventional computed tomography for damage analysis of composites, Composites Science and Technology 110 (2015) 62 - 68. doi:http: //dx.doi.org/10.1016/j.compscitech.2015.01.020.

[12] P. J. Schilling, B. R. Karedla, A. K. Tatiparthi, M. A. Verges, P. D. Herrington, X-ray computed microtomography of internal damage in fiber reinforced polymer matrix composites, Composites Science and Technology 65 (14) (2005) 2071 -2078. doi: http://dx.doi.org/10.1016/j.compscitech.2005.05.014.

[13] P. Wright, A. Moffat, I. Sinclair, S. Spearing, High resolution tomographic imaging and modelling of notch tip damage in a laminated composite, Composites Science and Technology 70 (10) (2010) 1444 - 1452. doi:http://dx.doi .org/10. $1016 /$ j .compscitech.2010.04.012

[14] A. Scott, I. Sinclair, S. Spearing, A. Thionnet, A. Bunsell, Damage accumulation in a carbon/epoxy composite: Comparison between a multiscale model and computed tomography experimental results, Composites Part A: Applied Science and Manufacturing 43 (9) (2012) 1514 - 1522. doi:http://dx.doi.org/10.1016/ j.compositesa.2012.03.011

[15] B. Yu, R. Bradley, C. Soutis, P. Hogg, P. Withers, 2D and 3D imaging of fatigue failure mechanisms of 3D woven composites, Composites Part A: Applied Science and Manufacturing 77 (2015) 37 - 49. doi:http://dx.doi.org/10.1016/j. compositesa.2015.06.013.

[16] D. R.-B. Aroush, E. Maire, C. Gauthier, S. Youssef, P. Cloetens, H. Wagner, A study of fracture of unidirectional composites using in situ high-resolution synchrotron Xray microtomography, Composites Science and Technology 66 (10) (2006) 1348 1353. doi:http://dx.doi.org/10.1016/j.compscitech.2005.09.010. 
[17] C. Chateau, L. Gélébart, M. Bornert, J. Crépin, E. Boller, C. Sauder, W. Ludwig, In situ X-ray microtomography characterization of damage in $\mathrm{SiCf} / \mathrm{SiC}$ minicomposites, Composites Science and Technology 71 (6) (2011) 916 - 924. doi : http: //dx.doi.org/10.1016/j.compscitech.2011.02.008.

[18] O. Caty, P. Ibarroule, M. Herbreteau, F. Rebillat, E. Maire, G. L. Vignoles, Application of X-ray computed micro-tomography to the study of damage and oxidation kinetics of thermostructural composites, Nuclear Instruments and Methods in Physics Research Section B: Beam Interactions with Materials and Atoms 324 (2014) 113 - 117, 1st International Conference on Tomography of Materials and Structures. doi:http://dx.doi.org/10.1016/j.nimb.2013.10.053

[19] H. A. Bale, A. Haboub, A. A. MacDowell, J. R. Nasiatka, D. Y. Parkinson, B. N. Cox, D. B. Marshall, R. O. Ritchie, Real-time quantitative imaging of failure events in materials under load at temperatures above $1,600 \mathrm{c}$, Nature materials 12 (1) (2013) 40-46. doi : 10.1038/nmat3497.

[20] B. K. Bay, T. S. Smith, D. P. Fyhrie, M. Saad, Digital volume correlation: threedimensional strain mapping using X-ray tomography, Experimental mechanics 39 (3) (1999) 217-226. doi : 10.1007/BF02323555.

[21] T. S. Smith, B. K. Bay, M. M. Rashid, Digital volume correlation including rotational degrees of freedom during minimization, Experimental Mechanics 42 (3) (2002) 272-278. doi : 10.1007/BF02410982.

[22] S. Roux, F. Hild, P. Viot, D. Bernard, Three-dimensional image correlation from Xray computed tomography of solid foam, Composites Part A: Applied Science and Manufacturing 39 (8) (2008) 1253 - 1265, full-field Measurements in Composites Testing and Analysis. doi:http://dx.doi.org/10.1016/j.compositesa. 2007.11 .011

[23] S. Roux, J. Réthoré, F. Hild, Digital image correlation and fracture: an advanced 
technique for estimating stress intensity factors of $2 \mathrm{D}$ and $3 \mathrm{D}$ cracks, Journal of Physics D: Applied Physics 42 (21) (2009) 214004.

[24] P. Leplay, J. Réthoré, S. Meille, M.-C. Baietto, J. Adrien, E. Maire, Analyse d'un test in situ de double-torsion par tomographie $\mathrm{X}$ et corrélation d'images 3D, in: 10e colloque national en calcul des structures, Giens, France, 2011, p. Clé USB.

[25] A. Bouterf, S. Roux, F. Hild, J. Adrien, E. Maire, S. Meille, Digital Volume Correlation applied to X-ray tomography images from spherical indentation tests on lightweight gypsum, Strain 50 (5) (2014) 444-453. doi : 10.1111/str.12101.

[26] A. Bouterf, J. Adrien, E. Maire, X. Brajer, F. Hild, S. Roux, Failure mechanisms of plasterboard in nail pull test determined by X-ray microtomography and Digital Volume Correlation, Experimental Mechanics 56 (8) (2016) 1427-1437. doi: 10. $1007 / \mathrm{s} 11340-016-0168-8$.

[27] T. Taillandier-Thomas, S. Roux, T. F. Morgeneyer, F. Hild, Localized strain field measurement on laminography data with mechanical regularization, Nuclear Instruments and Methods in Physics Research Section B: Beam Interactions with Materials and Atoms 324 (2014) 70 - 79, 1st International Conference on Tomography of Materials and Structures. doi:http://dx.doi.org/10.1016/j.nimb.2013. 09.033

[28] O. Caty, E. Maire, S. Youssef, R. Bouchet, Modeling the properties of closedcell cellular materials from tomography images using finite shell elements, Acta Materialia 56 (19) (2008) 5524 - 5534. doi:http://dx.doi.org/10.1016/j. actamat.2008.07.023

[29] S. Youssef, E. Maire, R. Gaertner, Finite element modelling of the actual structure of cellular materials determined by X-ray tomography, Acta Materialia 53 (3) (2005) 719 - 730. doi:http://dx.doi.org/10.1016/j.actamat.2004.10.024. 
[30] A. C. Kaya, P. Zaslansky, A. Nikolaus, C. Fleck, Tensile failure observations in sintered steel foam struts revealed by sub-micron contrast-enhanced microtomography, Materials and Design 105 (2016) 190 - 200. doi : http://dx .doi .org/10.1016/ j.matdes.2016.05.069.

[31] L. Huang, Y. Wang, Y. Miao, D. Swenson, Y. Ma, C.-F. Yen, Dynamic relaxation approach with periodic boundary conditions in determining the 3D woven textile micro-geometry, Composite Structures 106 (2013) 417 - 425. doi:http://dx . doi.org/10.1016/j.compstruct.2013.05.057

[32] A. Drach, B. Drach, I. Tsukrov, Processing of fiber architecture data for finite element modeling of 3D woven composites, Advances in Engineering Software 72 (2014) 18 - 27, special Issue dedicated to Professor Zdeněk Bittnar on the occasion of his Seventieth Birthday: Part 2. doi : http://dx.doi.org/10.1016/j. advengsoft.2013.06.006

[33] G. Couégnat, H. Ayadi, C. Saurat, E. Rohmer, Towards realistic geometric modeling of woven fabrics, in: 19th International Conference on Composite Materials (ICCM19), Montréal, Canada, 2013.

[34] I. Straumit, S. V. Lomov, M. Wevers, Quantification of the internal structure and automatic generation of voxel models of textile composites from X-ray computed tomography data, Composites Part A: Applied Science and Manufacturing 69 (2015) 150 - 158. doi:http://dx.doi.org/10.1016/j.compositesa. 2014 . 11.016

[35] N. Naouar, E. Vidal-Sallé, J. Schneider, E. Maire, P. Boisse, Meso-scale FE analyses of textile composite reinforcement deformation based on X-ray computed tomography, Composite Structures 116 (2014) 165 - 176. doi:http://dx.doi.org/10. $1016 / \mathrm{j}$. compstruct . 2014.04 .026

[36] Y. Gowayed, G. Ojard, R. Miller, U. Santhosh, J. Ahmad, R. John, Correlation of 
elastic properties of melt infiltrated sic/sic composites to in situ properties of constituent phases, Composites Science and Technology 70 (3) (2010) 435-441.

[37] C. Studholme, D. Hill, D. Hawkes, An overlap invariant entropy measure of 3D medical image alignment, Pattern Recognition 32 (1) (1999) 71 - 86. doi : http: //dx.doi.org/10.1016/S0031-3203(98)00091-0.

[38] C. Mulat, M. Donias, P. Baylou, G. Vignoles, C. Germain, Axis detection of cylindrical objects in 3D images, Journal of Electronic Imaging 17 (3) (2008) 03110810311089.

[39] S. Advani, C. Tucker, A tensor description of fiber orientation in short fiber composites, in: 43 rd Annual Technical Conference, Society of Plastics Engineers, Inc, 1985, pp. 1113-1118.

[40] A. Doitrand, C. Fagiano, F.-X. Irisarri, M. Hirsekorn, Comparison between voxel and consistent meso-scale models of woven composites, Composites Part A: Applied Science and Manufacturing 73 (2015) 143 - 154. doi : http://dx .doi .org/ $10.1016 / \mathrm{j}$. compositesa.2015.02.022

[41] INRIA, Automatic mesh generation and adaptation methods GAMMA, Online : https://www-roc.inria.fr/gamma/gamma/Accueil/index.en.html (25/08/2016).

[42] S. Mital, B. Bednarcyk, S. Arnold, J. Lang, Modeling of Melt-Infiltrated SiC/SiC composite properties, Tech. Rep. NASA/TM-2009-215806, E-17069, NASA Glenn Research Center, Cleveland, OH, United States (October 2009).

[43] R. Naslain, A. Guette, F. Rebillat, S. Le Gallet, F. Lamouroux, L. Filipuzzi, C. Louchet, Oxidation mechanisms and kinetics of SiC-matrix composites and their constituents, Journal of Materials Science 39 (24) (2004) 7303-7316. doi: 10.1023/B: JMSC.0000048745.18938.d5 
[44] A. Melro, P. Camanho, S. Pinho, Influence of geometrical parameters on the elastic response of unidirectional composite materials, Composite Structures 94 (11) (2012) 3223 - 3231. doi:http://dx.doi.org/10.1016/j.compstruct.2012.05. Q04.

[45] L. Gélébart, C. Colin, Effects of porosity on the elastic behaviour of CVI SiC/SiC composites, Journal of Nuclear Materials 386-388 (2009) 82 - 85, fusion Reactor MaterialsProceedings of the Thirteenth International Conference on Fusion Reactor Materials. doi:http://dx.doi.org/10.1016/j.jnucmat.2008.12.064.

[46] G. Couégnat, Approche multiéchelle du comportement mécanique de matériaux composites à renfort tissé, Ph.D. thesis, Ecole doctorale Science et Physique pour l’Ingénieur Université de Bordeaux 1 (2008). 